\title{
Coleta seletiva: percepção e conhecimento sobre o tema - uma pesquisa exploratória
}

\author{
Thiago Favarini Beltrame', Andressa Lhamby' \\ IUNIASSELVI
}

Selective collection: perception and knowledge about the subject - an exploratory research

\section{Resumo}

As questões ambientais estão cada vez mais presentes no cotidiano da população e do ambiente empresarial. A fim de se obter o desenvolvimento sustentável, práticas que visam à sustentabilidade são implantadas a todo o momento. Uma maneira de se alcançar esse desenvolvimento é a gestão de resíduos sólidos, através da coleta seletiva. A melhor destinação dos resíduos sólidos é capaz de construir uma população sustentável do ponto de vista social e ambiental, através da redução dos resíduos produzidos, da reutilização e reciclagem de materiais como alternativa de renda. Este trabalho possui como objetivo identificar a percepção de um grupo de estudantes em relação ao conhecimento sobre coleta seletiva. Através do estudo, constatou-se que os entrevistados possuem conhecimento a respeito da coleta seletiva, porém poucos a realizam. Ainda, percebeu-se que não há uma grande identificação desse tipo de coleta de resíduos sólidos nas cidades dos entrevistados, evidenciando que a mesma necessita ser implantada e divulgada em escalas maiores.

Palavras Chave: Gestão Ambiental; Resíduos Sólidos; Coleta Seletiva

\begin{abstract}
Environmental issues are more and more present in everyday population and in corporate environment. In order to obtain sustainable development, practices aimed to the sustainability are developed every time. One way to achieve this development is the management of solid waste, through the selective collection. The best disposal of solid waste can build a sustainable population in the social and environmental viewpoint, through the reduction of waste generated, reuse and recycling of materials as an alternative income. This work aims to diagnose the perception of a group of students in relation to knowledge of selective collection. By this study it was verified that the interviewees have knowledge about the selective collection, but few of them do it. It was perceived too that there is not a meaningful identification on the part of the interviewees about the solid waste collection in their cities, indicating that this kind of practice needs to be disseminated and implemented on ample scales.
\end{abstract}

Keywords: Environmental Management; Solid Waste; Selective Collection. 


\section{INTRODUÇÃo}

Desde a década de 70 a preocupação ambiental vem fazendo parte do panorama mundial. As questões ambientais vêm sendo discutidas em vários debates, reuniões, congressos, conferencias, entre outros. Conceitos referentes à gestão ambiental surgiram no panorama nacional e mundial. Segundo Tinoco e Kraemer (2004), a gestão ambiental é: "o sistema que inclui a estrutura organizacional, atividades de planejamento, responsabilidades, práticas, procedimentos, processos e recursos para desenvolver, implementar, atingir, analisar criticamente e manter a política ambiental". Assim, percebe-se que a temática envolvendo a gestão ambiental está cada vez mais presente no cotidiano dos cidadãos. Uma forma de gestão ocorre por meio da gestão dos resíduos sólidos e desenvolvimento sustentável.

Conceitos relativos ao desenvolvimento sustentável estão cada vez mais presentes em instituições e organizações. De acordo com a Organização das Nações Unidas - ONU desenvolvimento sustentável é "aquele que atende às necessidades presentes sem comprometer a possibilidade de que as gerações futuras satisfaçam as suas próprias necessidades". Os resíduos sólidos gerados são elementos fundamentais na busca deste tipo de desenvolvimento benéfico às pessoas e ao meio ambiente.

O gerenciamento dos resíduos sólidos inclui atividades visando à redução de resíduos na fonte, coleta seletiva e reciclagem, compostagem dos resíduos orgânicos; construção de aterros sanitários e outras formas de destinação final de resíduos não recicláveis, têm se mostrado como a solução mais eficiente no que diz respeito ao desenvolvimento sustentável (BELTRAME et al., 2012). A proteção ao meio ambiente deixa de ser uma exigência punida com multas e sanções e se inscreve em um quadro de ameaças e oportunidades, em que as consequências têm impacto sobre a sobrevivência da organização (DONAIRE, 1994).

Uma alternativa para a busca da sustentabilidade, referente à temática de resíduos sólidos, é a implantação da coleta seletiva e a prática de reciclagem. A coleta seletiva de "lixo" é um processo que consiste na separação e recolhimento de resíduos descartados, visando à reciclagem. Os materiais que podem ser reciclados tais como papéis, metais, plásticos e vidros são separados do lixo orgânico (biodegradável). A prática de reciclagem é um processo que contribui para a preservação dos recursos naturais, economiza energia, recupera e reusa matérias-primas.

Este trabalho possuiu como objetivo identificar a percepção de um grupo de estudantes em relação à prática de coleta seletiva através do uso metodológico de uma pesquisa exploratória.

\section{Referencial Bibliográfico}

\section{I Coleta Seletiva}

A preocupação com as questões ambientais advém desde a década de 70. Naquela época, houve a Conferência de Estocolmo, na Suécia, cujo tema principal foi à poluição industrial. Já no início de 1990 houve no Rio de Janeiro - Brasil - o ECO 92, conferência a qual debateu o desenvolvimento econômico, com influência direta sobre a educação ambiental. Nos anos 2000, diversos eventos, conferências e encontros ocorreram com o propósito de debates as questões relativas ao meio ambiente. Dentre os muitos temas abordados nestes eventos, destaca-se a geração de resíduos sólidos.

Sabe-se que a definição de lixo, ou resíduo, consiste em ser qualquer material considerado inútil, supérfluo, e/ou sem valor, gerado pela atividade humana. Logo, pode-se inferir que é qualquer material cujo ser humano elimina, deseja eliminar ou necessita eliminar. Segundo a NBR ISO 10004 (2004), resíduos sólidos são aqueles:

...os quais resultam de atividades de origem industrial, doméstica, hospitalar, comercial, agrícola, de serviços e de varrição. Ficam incluídos nesta definição os lodos provenientes de sistemas de tratamento de água, aqueles gerados em equipamentos e instalações de controle de poluição, bem como determinados líquidos cujas particularidades tornem inviável o seu lançamento na rede pública de esgotos ou corpos de água, ou exijam para isso soluções técnica e economicamente inviáveis em face à melhor tecnologia disponível (NBR, 2004).

Os resíduos podem passar por uma segregação, que dê origem a ações que corroborem a ocorrência da responsabilidade social e desenvolvimento sustentável. A Responsabilidade Social-RS tem assumido crescente relevância nos meios acadêmico e empresarial, sendo cada vez maior a exploração do tema e os debates acerca dele (OLIVEIRA, 2010). Em relação ao desenvolvimento sustentável, sabe-se que o mesmo tornou-se requisito mínimo nas instituições públicas e 
privadas. Um meio de minimizar os impactos ambientais negativos causados pela geração dos resíduos sólidos e praticar o desenvolvimento sustentável juntamente com a responsabilidade social é a realização da coleta seletiva.

Garbossa (2010) diz que a prática de coleta seletiva é baseada em um sistema de recolhimento diferenciado, no qual se faz a separação previa de papéis, plásticos, vidros, metais e resíduos orgânicos. Esses materiais recicláveis, após um pré-beneficiamento, que inclui a separação por cores, tipos e prensagem são vendidos a indústrias recicladoras ou aos atravessadores (sucateiros), para que desta forma possam ser transformados por indústrias recicladoras e voltar para o mercado (MORAES, 2011).

A realização da coleta seletiva traz consigo grandes benefícios como, por exemplo, a possibilidade de fazer-se a reciclagem. De acordo com Valle (2002) o ato de reciclar é refazer um ciclo e permite retomar a origem na forma de matérias primas, dos materiais que não se degradam facilmente e que podem ser reprocessados, mantendo as suas características básicas. A reciclagem tornou-se uma tendência mundialmente disseminada e como visto consiste no reaproveitamento dos produtos para a fabricação de novos objetos, o que se mostra uma das alternativas mais importantes no processo de desenvolvimento sustentável. Ou seja, a coleta seletiva é algo de sumo importância nos dias atuais, pois proporciona o alcance à sustentabilidade de forma relativamente simples e com o envolvimento de todos.

\section{Metodologia}

A pesquisa utilizada neste trabalho é classificada como exploratória. Neste tipo de pesquisa, obtêm-se, na maioria das vezes, descrições qualitativas e quantitativas do objeto de estudo, e o investigador deve conceituar as inter-relações entre as propriedades do fenômeno, fato ou ambiente observado (LAKATOS e MARCONI, 2010). O estudo é classificado como de caso. De acordo com Triviños (1987), o estudo de caso "é uma categoria de pesquisa cujo objeto é uma unidade que se analisa exaustivamente". Para Yin (2001) "o estudo de caso é usado em muitas situações, para contribuir ao nosso conhecimento dos fenômenos individuais, grupais, organizacionais, sociais, políticos e relacionados".

O delineamento assumiu a forma de levantamento de dados dirigidos a uma população, seguido da apuração analítica dos dados. Optou-se pela realização de uma amostragem por conglomerado de pessoas ligadas à área de gestão ambiental (HAIR JR., 2005; HAIR JR., 2010; SILVA, 2004; MORAES, 2011). Elaborou-se um instrumento de coleta de dados na forma de questionário com questões fechadas, composto por 10 questões sendo algumas com o objetivo de caracterizar os participantes da amostragem. Ainda, além das respostas fechadas, fez-se uso da identificação do grau de "importância", no qual 1 (um) representa a menor importância, e 5 (cinco) representa a maior importância para determinadas questões. Atribuiu-se peso 5 como "mais importante"; 4 "importante"; 3 "mais ou menos importante"; 2 "pouco Importante' e, 1 "menos importante". Este tipo de coleta de dados é chamado de escala Likert. Para Mattar (2001) as principais vantagens da utilização deste tipo de escala consiste na sua simplicidade de construção e na amplitude de respostas permitidas, apresentando informações mais precisas na opinião do entrevistado em relação a cada afirmação. Fez-se a aplicação destes questionários a partir de visitas as salas de aula e com alunos que circulavam pela universidade. Os dados obtidos pelos questionários respondidos foram tabulados em planilhas.

\section{Resultados e discussões}

Do montante dos entrevistados $75 \%$ são do gênero feminino e $25 \%$ do masculino.

Questionou-se o conhecimento dos entrevistados frente ao conceito de coleta seletiva e todos os entrevistados, ou seja, $100 \%$ sabem o que significa esta prática e conhecem a mesma.

Em relação ao conhecimento de algum programa de coleta seletiva em suas cidades, notou-se que $54 \%$ dos entrevistados não possui contato com essa prática (Figura 1).

Quando questionados sobre como ocorre a coleta seletiva dos resíduos urbanos na sua cidade de origem, os entrevistados, em maioria (67\%) disseram saber e conhecer o procedimento, mesmo que de forma superficial (Figura 2).

Verificou-se que, quanto à percepção dos entrevistados sobre a importância de se praticar a coleta seletiva, os mesmos consideram muito importante ou importante - 95\% - (Figura 3) a ocorrência desse tipo de programa. Logo, verifica-se que há campo para o ensino e prática da coleta seletiva.

Foi questionado se os entrevistados possuem a preocupação em diminuir a quantidade de resíduos sólidos (lixo) que é gerado em suas 


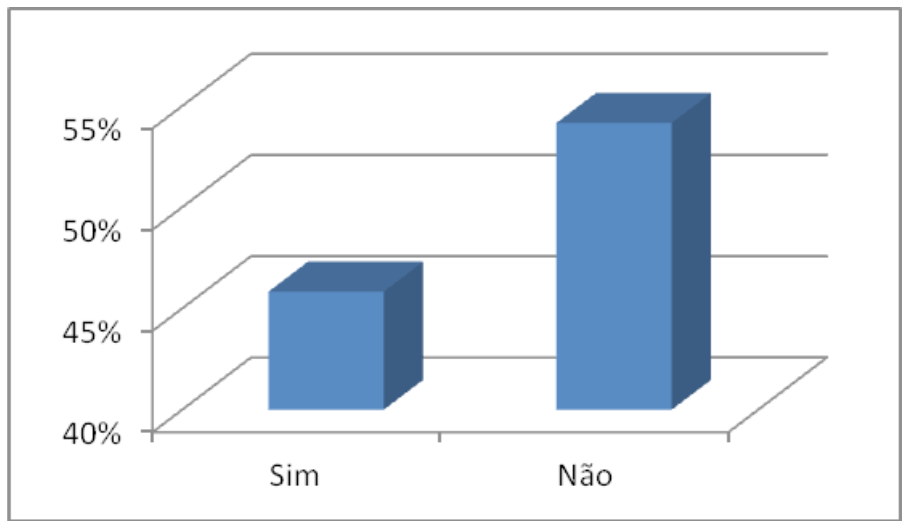

Figura 1 - Conhecimento do entrevistado a respeito de programas de coleta seletiva na sua cidade de origem.

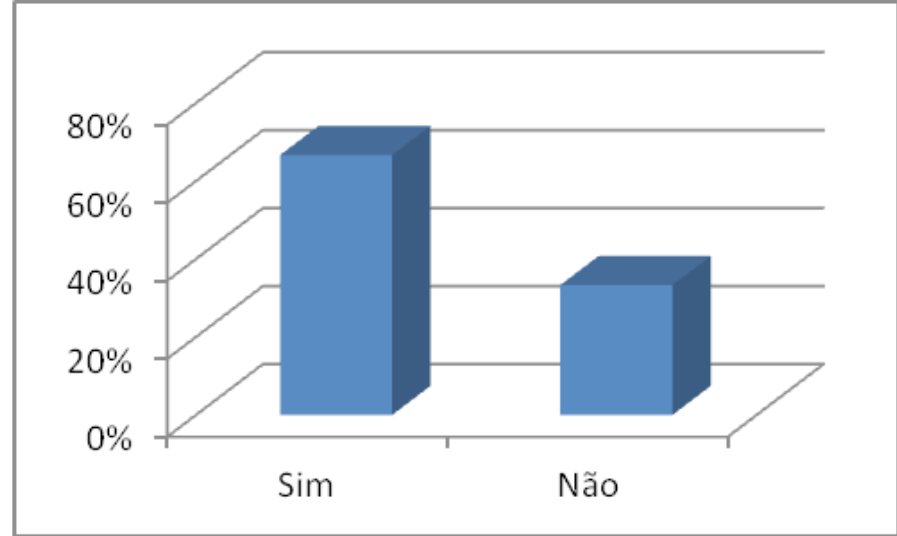

Figura 2 - Conhecimento de como ocorre à prática de coleta seletiva na cidade de origem do entrevistado.

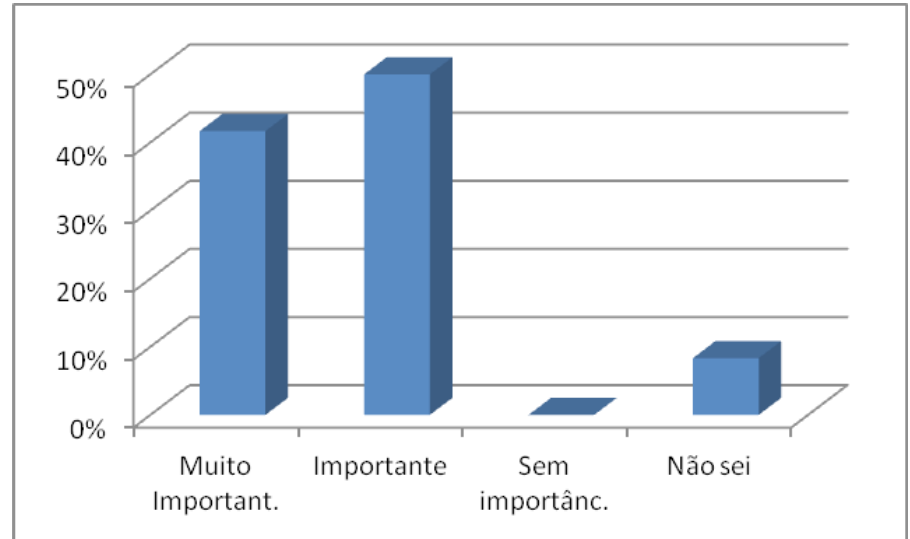

Figura 3 - Importância de realizar a coleta seletiva na opinião dos pesquisados.

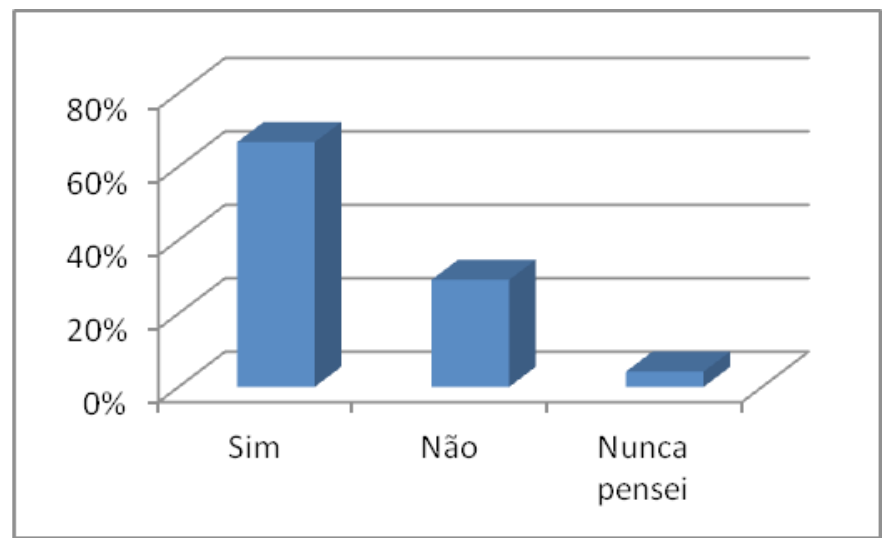

Figura 4 - Preocupação dos entrevistados em diminuir a quantidade de resíduos sólidos produzidos. 


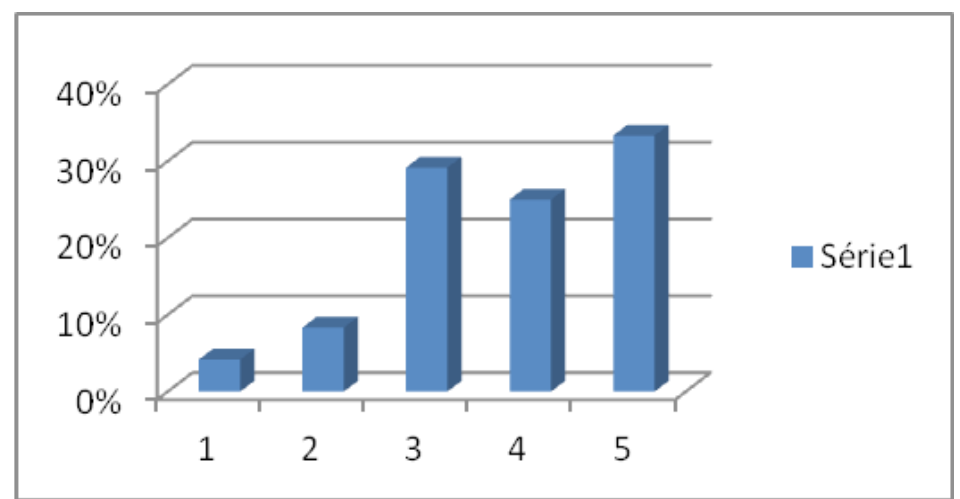

Figura 5 - Grau de importância da relação entre coleta seletiva e a preservação do meio ambiente, na opinião dos entrevistados.

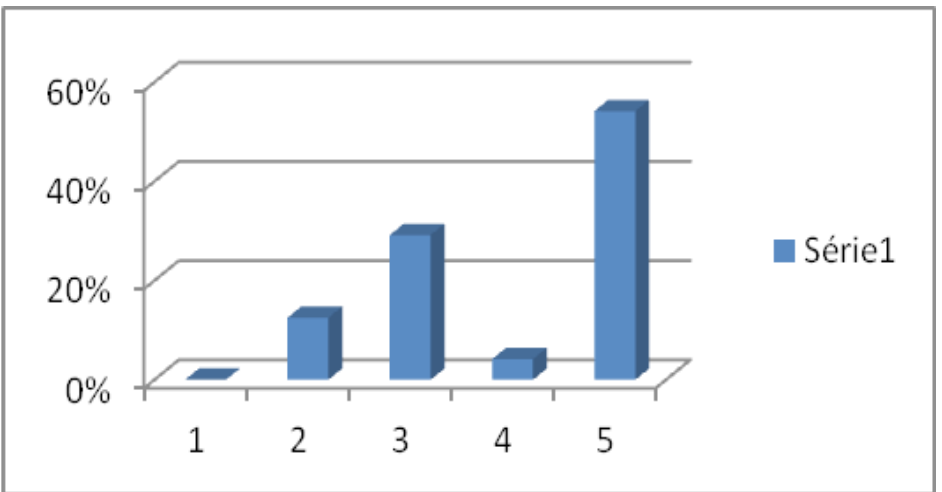

Figura 6 - Grau de importância da relação entre coleta seletiva e imagem da empresa/organização, na opinião dos entrevistados.

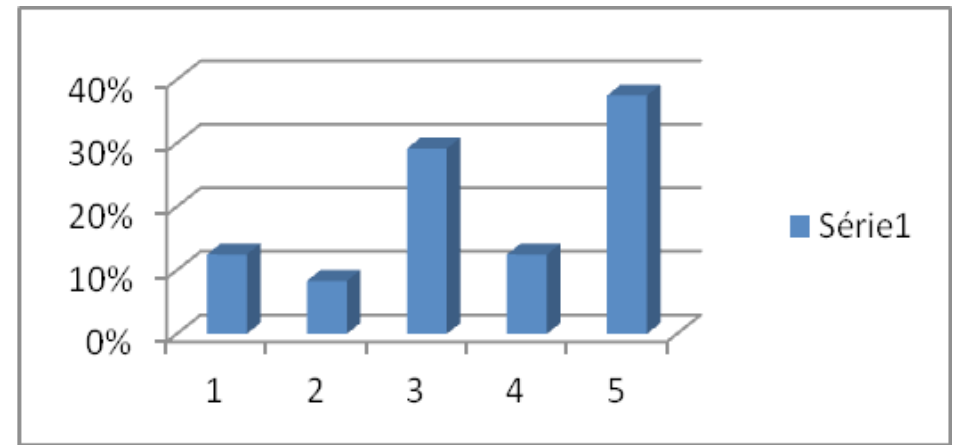

Figura 7 - Grau de importância da relação entre coleta seletiva e responsabilidade socioambiental, na opinião dos entrevistados.

residências. Notou-se que $67 \%$ dos respondentes já pensaram em realizar essa minimização dos resíduos.

Abordou-se, por meio de uma escala de 1 a 5, o grau de importância na visão do entrevistado a respeito da: relação entre a prática de coleta seletiva e a preservação do meio ambiente; relação entre a prática da coleta seletiva e a imagem de instituições/organizações perante a sociedade e, por fim, a importância entre a prática de coleta seletiva e a responsabilidade socioambiental; sendo o peso (1) para o menos importante e (5) para mais importante, os resultados são apresentados nas figuras 5, 6 e 7 .

Percebe-se que os entrevistados relatam ser importante a prática da coleta seletiva em relação à imagem de instituições/organizações perante a sociedade, ou seja, quando a empresa pratica programas ambientalmente corretos a sua imagem para a sociedade é melhorada. Ainda, nota-se que cerca de $60 \%$ acreditam que a coleta seletiva trás benefícios ao meio ambiente de forma direta. Quanto ao grau de relação entre a coleta seletiva de resíduos sólidos e a questão socioambiental identifica-se que aproximadamente $70 \%$ acreditam ser diretamente proporcional. 


\section{Considerações Finais}

Ao fim do trabalho, pode-se concluir que os entrevistados identificam a importância da prática da coleta seletiva para o meio ambiente e a reconhecem como um fator de diferencial a uma organização, porém, algumas vezes, falta um conhecimento mais aprofundado a respeito do assunto. Nota-se que a maioria dos participantes da pesquisa acredita que a prática de coleta seletiva é importante para a sustentabilidade e auxilia na preservação do meio ambiente, mas não conhecem, em suas cidades de origem, este tipo de coleta sustentável. Ainda, é possível verificar que grande parte dos entrevistados acredita que a coleta seletiva é importante/muito importante e averiguou-se que grande parte dos respondentes possui uma preocupação em reduzir os resíduos sólidos produzidos pelos mesmos. Logo, vê-se que a temática coleta seletiva é algo de sumo importância para a sociedade em geral e deve ser abordado de forma ampla, além de ser implantada. Deve-se debater o tema em congressos, reuniões, simpósios e cada vez mais se necessita de incentivos para o desenvolvimento de programas voltados a sustentabilidade, como o abordado neste trabalho; a coleta seletiva.

\section{RefERÊnCIAS BibliográficAs}

ANDRADE, Rui Otávio; Bernardes de. TACHIZAWA, Takeshy.; CARVALHO, Ana Barreiros de. Gestão Ambiental: Enfoque Estratégico Aplicado ao Desenvolvimento Sustentável. São Paulo: MAKRON books, 2000.

\section{CONGRESSO NACIONAL DE GESTÃO} AMBIENTAL. BELTRAME, Thiago Favarini; LHAMBY, Andressa Rocha; SOARES, Aline; SCHMIDT, Alberto Souza. Diagnósticos dos resíduos e viabilidade de implantação de coleta seletiva em um município do Rio Grande do Sul. Terceiro Congresso Nacional de Gestão Ambiental, Goiás, 2012.

COELHO, M. R. F. Coleta Seletiva. Secretaria do Meio Ambiente. São Paulo, 2001.

DONAIRE, Denis. Gestão ambiental na empresa. $2^{\mathrm{a}}$ ed. São Paulo: Editora Atlas, 1999.

FELIX, Rozeli Aparecida Zanon. Coleta seletiva em ambiente escolar. Revista Eletrônica do Mestrado em Educação Ambiental. Vol. 18. 2007.

GOMES, Alessandro. A gestão do sistema ambiental e a NBR ISSO 14001. Revista Científica Eletrônica de Administração. no 11. Garça 2006.

HAIR, Júnior. Fundamentos de métodos de pesquisa em administração. Porto Alegre: Bookman, 2005.

INSTITUTO BRASILEIRO DE GEOGRAFIA E ESTATÍSTICA - IBGE. Estatísticas de Empreendedorismo. Rio de Janeiro, 2011. Disponível em: $<$ http://biblioteca.ibge.gov.br/visualizacao/monografias/GEBIS\%20\%20RJ/empreendedorismo_2008. pdf $>$ Acessado em: 10 de outubro de 2012.

MARCONI, Marina Andrade de., LAKATOS, Eva Maria. Fundamentos de metodologia cientifica. $7^{\mathrm{a}}$ ed. São Paulo: Atlas, 2010.

MORAES, F.G. ACAMART: Autogestão e participação na cadeia produtiva. É possível? Revista Geográfica de América Central. Número Especial EGAL, 2011.

MATTAR, Fauze Najib. Pesquisa de marketing. Edição Compacta. $3^{a}$ ed. São Paulo: Atlas, 2001.

PIVA, Carla; BONONI, Vera Lúcia Ramos; FIGUEIREDO, Regina Sueiro; SOUZA, Celso Correia de. Sistema de Gestão Ambiental implementado aos moldes da ISO 14001:2004 em um frigorífico de abate de aves, no Município de Sidrolândia - Mato Grosso do Sul. Revista Brasileira de Gestão e Desenvolvimento Regional. v. 3, n. 3, p. 20-53, set-dez/2007.

SILVA, Nilza Nunes da. Amostragem probabilística: um curso introdutório. 2. ed. São Paulo: USP, 2004.

TINOCO, João E. Prudêncio; KRAEMER, Maria Elisabeth Pereira. Contabilidade e gestão ambiental. São Paulo: Atlas, 2004.

TRIVINÕS, A.N.S. Introdução à pesquisa em ciências sociais: a pesquisa qualitativa em educação. São Paulo: Atlas, 1987.

VALLE, Cyro Eyer. Qualidade ambiental: ISO 14000. $4^{a}$ ed. São Paulo: SENAC, 2002.

YIN, Robert K. Estudo de Caso: Planejamento e Métodos. $2^{\mathrm{a}}$ ed. Porto Alegre: Bookman, 2001. 